\title{
Estratégias de customização em massa implementadas por empresas brasileiras
}

\author{
André Gustavo Carvalho Machado \\ UFPB \\ Walter Fernando Araújo de Moraes \\ UFPE
}

\begin{abstract}
Resumo
O objetivo deste artigo é analisar as estratégias de customização em massa implementadas por empresas brasileiras. Neste sentido, a estratégia de pesquisa adotada foi de estudo de casos múltiplos, empreendido em quinze empresas, abrangendo nove diferentes divisões de atividades econômicas. A entrevista foi a principal técnica de coleta de dados. A análise dos dados, por seu turno, ocorreu em dois estágios: análise individual e análise cruzada dos casos. Ao se analisar as ações empreendidas no processo de customização dos produtos e serviços das empresas selecionadas, constatou-se que duas estratégias se destacaram: modularidade e postergação da manufatura. Ademais, evidenciou-se que a maioria das empresas executa suas atividades de customização em diferentes estágios da cadeia de valor, oferecendo, pelo menos, dois níveis de customização para o mercado. Foi também elaborado um continuum, representando as diferenças entre o grau de customização de cada empresa analisada.
\end{abstract}

\section{Palavras-chave}

Estratégias, customização em massa, modularidade, postergação.

\section{Strategies of mass customization accomplished by brazilian companies}

\begin{abstract}
The objective of this paper is the analysis of the strategies of mass customization accomplished by Brazilian companies. Therefore, the research strategy adopted was a multiple-case study, which was undertaken in fifteen companies, comprising ten different divisions of economic activities. Interviews were the main technique for collecting data. The analysis of data, in its turn, took place in two phases: within-case analysis and cross-case analysis. When analyzing the actions undertaken in the customization process of the products and services of the selected companies, it was verified that two strategies stood out: modularity and manufacturing postponement. Furthermore, it was proved that most companies carry out their customization activities in different stages of the value chain, offering the market two customization levels, at least. A continuum was also developed, representing the differences among the degrees of customization of each analyzed company.
\end{abstract}

Key words

Strategies, mass customization, modularity, postponement. 


\section{INTRODUÇ̃̃O}

A estratégia de customização em massa pode ser entendida como o conjunto de planos que irá servir de referência para a tomada de decisões (associadas à alocação de recursos e implementação de ações), no sentido de satisfazer às necessidades individuais dos clientes, por meio da rápida disponibilização de bens e serviços de forma eficiente e em grande escala. Ela representa, portanto, a possibilidade de prover um valor único para cada comprador, podendo se constituir numa fonte de vantagem competitiva para a empresa (MACCARTHY; BRABAZON, 2003). Como conseqüência provável da execução desta estratégia, a empresa estaria apta a alcançar um desempenho superior (JIAO; MA; TSENG, 2001).

Apesar da sua importância, a revisão da literatura permite concluir que há uma carência de estudos mais aprofundados, no âmbito nacional, sobre as estratégias de customização em massa, indicando que pesquisas devam ser empreendidas no sentido de melhor conhecer como este fenômeno está sendo tratado pelas empresas brasileiras. Deste modo, o problema de pesquisa foi formulado da seguinte maneira: quais estratégias de customização em massa estão sendo executadas pelas empresas brasileiras?

Com o intuito de responder à questão formulada no problema de pesquisa, o objetivo central deste artigo consistiu em analisar as estratégias de customização em massa implementadas por empresas brasileiras. Para isto, o artigo está estruturado da seguinte forma: inicialmente será apresentado um breve referencial teórico sobre o tema. Em seguida, serão esclarecidos os procedimentos metodológicos e realizada a análise cruzada dos casos selecionados. Por fim, são delineadas as conclusões.

\section{ESTRATÉGIAS DE CUSTOMIZAC̣̃̃O EM MASSA}

A análise dos trabalhos desenvolvidos por diversos autores (SPIRA, 1993; PINE, 1994; LAMPEL; MINTZBERG, 1996; GILMORE; PINE, 1997; DURAY et al., 2000; ALFORD; SACKETT; NELDER, 2000; SILVEIRA; BORESTEIN; FOGLIATTO, 2001) evidencia que as diferenças entre as estratégias de customização em massa estão relacionadas, principalmente, aos pontos onde ocorre a customização, podendo ser tanto dentro quanto fora dos limites da empresa.

Após analisar os procedimentos adotados para operacionalização da customização em massa numa empresa norteamericana, fabricante de sistemas de controle de iluminação, Spira (1993) sugere quatro diferentes modos para atingir aquele alvo: montagem de produtos adotando uma combi- nação de componentes padronizados, de forma a resultar em diferentes variações de modelos; serviços especiais agregados aos produtos disponibilizados, tais como pintura dos produtos com cores diferenciadas e integração com sistemas de segurança em separado; customização da embalagem; e trabalho de customização adicional, caso as opções disponibilizadas não atendam às necessidades do cliente.

Com o objetivo de propor caminhos alternativos que uma empresa possa seguir para atingir a customização em massa, Pine (1994) identificou cinco estratégias básicas, não mutuamente exclusivas, que são: customizar serviços em torno de produtos e serviços padronizados; criar produtos e serviços customizáveis; prover pontos de entrega de customização; fornecer respostas rápidas por toda a cadeia de valor; e modularizar componentes para customizar produtos finais e serviços. As estratégias propostas se diferenciam entre si de acordo com os esforços empreendidos sobre certas atividades (projeto, produção, marketing e distribuição) que são partes componentes da cadeia de valor, com o objetivo de padronizar e customizar os produtos e serviços a serem disponibilizados.

\section{A diferenças entre as estratégias de customização em massa estão relacionadas, principalmente, aos pontos onde ocorre a customização.}

A cadeia de valor se constitui de atividades de valor e margem. "As atividades de valor são as atividades físicas e tecnologicamente distintas, através das quais uma empresa cria um produto valioso para seus compradores. A margem é a diferença entre o valor total e o custo coletivo da execução das atividades de valor" (PORTER, 1989, p. 34). Assim, destaca o autor, "toda empresa é uma reunião de atividades que são executadas para projetar, produzir, comercializar, entregar e sustentar seu produto".

Analisando a extensão pela qual uma empresa pode customizar o produto ao longo de quatro outros estágios da cadeia de valor (projeto, fabricação, montagem e distribuição), Lampel e Mintzberg (1996) definiram um continuum de cinco diferentes níveis de estratégia (Figura 1). Estes autores entendem que a diferença entre as estratégias está na localização do ponto na cadeia de valor, a partir do qual será realizada a customização.

Por sua vez, Gilmore e Pine (1997) identificaram quatro abordagens para customização: colaborativa, adaptativa, cosmética, e transparente. As quatro abordagens propostas por estes autores não são mutuamente exclusivas, no entan- 
to, são dependentes dos objetivos estratégicos da organização, bem como das características próprias dos produtos e serviços a serem disponibilizados. Cada uma delas apresenta complexidade de operação distinta, envolvendo custos e esforços particulares e tem o intuito de prover um framework que auxilie as empresas na determinação do tipo de customização a ser perseguida.

montadores. O Quadro 1, resume a proposta de classificação.

Nesse estudo, diferente dos demais, a exigência da modularidade é o fator crítico e diferenciador no modelo proposto, pois até então a existência de módulos não era contemplada em todos os níveis de customização. Duray et al. (2000), a exemplo de Pine (1994), entendem que é por meio da adoção de módulos que a estratégia de customização em massa é viabilizada.

Assim, a modularidade por compartilhamento de componentes é usada para permitir economias de escopo, na medida em que o mesmo componente é utilizado em múltiplos produtos. No tipo de modularidade

A análise dos trabalhos sobre as estratégias de customização em massa evidencia que há certas semelhanças na taxionomia adotada, que parecem se repetir ao longo dos estudos. Isto ocorre de forma mais visível em termos de duas dimensões: participação do cliente na customização do produto e os estágios onde ocorrem a customização ao longo da cadeia de valor.

Nesta perspectiva, Duray et al. (2000) classificaram a customização em massa em termos de duas características: o ponto no qual há o envolvimento do cliente e o tipo de modularidade empregada para prover produtos customizados. A justaposição das duas características origina quatro categorias (ou grupos) de customização em massa: fabricantes, envolvidos, modularizadores e por ajuste de componentes, um ou mais componentes podem variar suas dimensões físicas (largura, altura, comprimento) dentro dos limites preestabelecidos ou práticos antes de se combinar com outros módulos. É usado quando é exigido que os produtos tenham dimensões únicas.

A modularidade por mix pode utilizar quaisquer dos tipos já apresentados. Entretanto, quando os componentes são combinados, estes perdem sua identidade, tornado-se diferentes. No caso da modularidade por permuta, componentes diferentes são emparelhados no mesmo produto básico, criando tanto produtos quantos componentes para permuta existirem.

O tipo de modularidade por bus é caracterizado por possuir uma estrutura que pode receber um número de di-

Figura 1: Continuum de Estratégias.

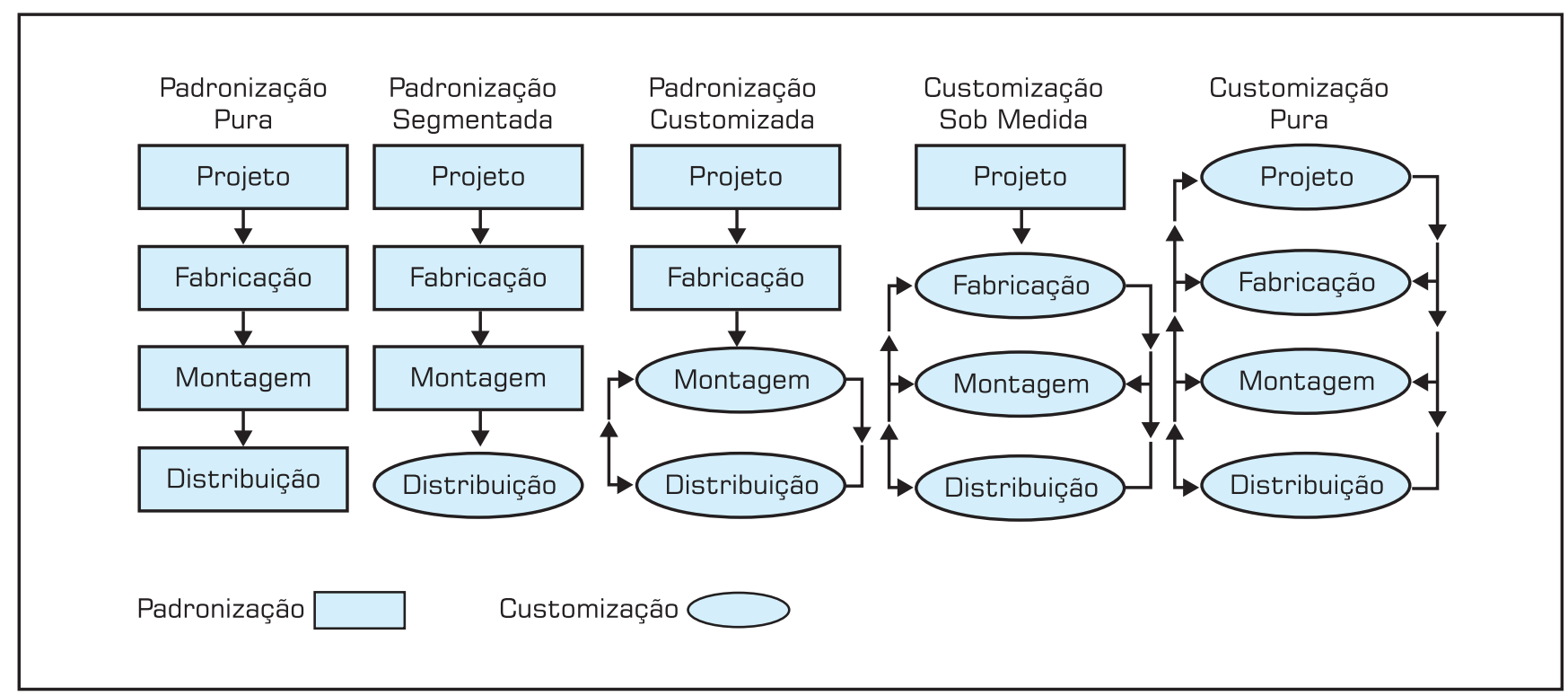

Fonte: Lampel e Mintzberg, 1996, p.24 
ferentes tipos de componentes que se conectam utilizando o mesmo tipo de interface. Assim, sua distinção-chave é que uma estrutura padronizada permite a variação no tipo, número e local dos módulos que podem se encaixar. Por fim, a modularidade seccional possibilita a configuração de qualquer número de diferentes tipos de componentes em meios arbitrários, desde que cada componente possa ser conectado a um outro por meio de interfaces padrões.

Especificamente no contexto da indústria automotiva, Alford, Sackett e Nelder (2000) identificam três estratégias distintas para customização, são elas: customização essencial (core customisation); customização facultativa (optional customisation); e customização da aparência (form customisation). Estas estratégias, a exemplo das demais apresentadas, refletem a progressiva integração do cliente com as atividades da cadeia de valor, envolvendo projeto, montagem e distribuição.

Apesar das estratégias supracitadas já estarem sendo implementadas no âmbito da indústria automobilística, o desafio para o setor continua sendo encontrar o melhor meio de satisfazer às necessidades individuais dos consumidores, sem comprometer os custos de produção e comercialização, qualidade e o prazo de entrega. O problema central, todavia, está relacionado ao fato de que, para a maioria dos veículos, apenas um número limitado de atributos pode, atualmente, ser personalizado, sugerindo que são necessários maiores esforços para atender às exigências dos consumidores, sem afetar o desempenho do sistema produtivo.

Os trabalhos de Spira (1993), Pine (1994), Lampel e Mintzberg (1996) e Gilmore e Pine (1997) foram analisados por Silveira, Borestein e Fogliatto (2001), o que possibilitou o desenvolvimento de uma classificação genérica, envolvendo oito diferentes níveis de customização em massa: projeto (refere-se ao projeto colaborativo, além da possibilidade da fabricação e da entrega atuarem de forma a atender às necessidades dos clientes); fabricação (refere-se à fabricação de produtos por encomenda, a partir de projetos padronizados); montagem (refere-se ao uso de componentes modulares para gerar configurações variadas); trabalho customizado adicional (oferecimento de trabalho adicional para atender necessidades específicas); serviço adicional (oferecimento de serviço adicional para atender necessidades específicas); embalagem e distribuição (customização das embalagens e formas de distribuir os produtos); utilização (a customização é realizada após a entrega do produto, sendo efetuada pelo próprio cliente); e, por fim, padronização (disponibilização de produtos padronizados).

Observa-se, novamente, a adoção da perspectiva da cadeia de valor para distinção entre os níveis sugeridos. A apresentação dos níveis de forma individualizada pode dar a falsa impressão de que eles são mutuamente excludentes. Não é o caso. Conforme alertam Carmo e Gavronski (2002), assim como MacCarthy, Brabazon e Bramham (2003), pode haver mais do que um nível de customização oferecido por uma empresa a seus clientes.

Ademais, a localização de diferentes pontos a partir dos quais será executada a customização está associada ao conceito de postergação (postponement), isto é, o retardamento de certas atividades de diferenciação do produto ou do serviço até o recebimento do pedido do cliente (VAN HOEK, 2001).

\section{Quadro 1: Categorias de Customização em Massa.}

\begin{tabular}{|c|c|c|c|c|}
\hline \multirow[b]{2}{*}{ TIPO DE MODULARIDADE } & \multicolumn{4}{|c|}{ PONTO DE ENVOLVIMENTO DO CLIENTE } \\
\hline & Projeto & Fabricação & Montagem & Uso \\
\hline Compartilhamento de Componentes & \multirow{2}{*}{\multicolumn{2}{|c|}{ Fabricantes }} & \multirow{2}{*}{\multicolumn{2}{|c|}{ Modularizadores }} \\
\hline Ajuste de Componentes & & & & \\
\hline \multicolumn{5}{|l|}{ Mix } \\
\hline Permuta de Componentes & \multirow{3}{*}{\multicolumn{2}{|c|}{ Envolvidos }} & \multirow{3}{*}{\multicolumn{2}{|c|}{ Montadores }} \\
\hline Bus & & & & \\
\hline Seccional & & & & \\
\hline
\end{tabular}

Fonte: adaptado de Duray et al., 2000, p. 612-614. 
Nesta perspectiva, diferentes níveis de postergação podem ocorrer de acordo com o local na cadeia de suprimentos em que o produto é customizado, tais como postergação da manufatura (ZINN, 1990; HERMANSKY; SEELMANNEGGEBERT, 2003; YANG; BURNS; BACKHOUSE, 2004) e da logística (BOWERSOX; CLOSS, 2001; YANG; BURNS; BACKHOUSE, 2004) ou distribuição (WALLER; DABHOLKAR; GENTRY, 2000).

O objetivo da postergação da manufatura é aumentar o potencial de se trabalhar internamente com escala de produção e de forma mais eficiente, sem comprometer a variedade de produtos finais, padronizando o processo produtivo até o mais próximo possível da área de expedição e entrega aos clientes. Isto permite que sejam executados diferentes tipos de postergação: fabricação, montagem, embalagem e etiquetagem (ZINN, 1990).

A postergação da fabricação significa que a fabricação só é concluída após o recebimento de um pedido do cliente. A postergação da montagem, por sua vez, está associada ao retardamento das tarefas de montagem do produto até que se receba o pedido do cliente. Isto é possível quando um produto básico é vendido em configurações diferentes, mas semelhantes, que refletem as preferências individuais dos clientes.

A postergação de embalagem, por seu turno, significa adiar a tarefa de embalar o produto até a definição das necessidades do cliente, sendo viável para produtos vendidos em embalagens de características físicas (tamanhos, volumes e formas) diferentes. Outra utilidade deste tipo de postergação está na diferenciação dos manuais de utilização do produto, de acordo com o idioma corrente do mercado consumidor, por exemplo.

A postergação de etiquetagem diz respeito ao armazenamento de produtos sem qualquer rótulo ou identificação da marca, os quais apenas são afixados mediante a chegada de um pedido do cliente especificando a marca desejada.

Um importante requisito para a postergação da manufatura consiste na possibilidade de dividir o processo produtivo em, pelo menos, dois estágios: primário e secundário (VAN HOEK; COMMANDEUR; VOS, 1998). O estágio primário seria responsável pela produção de componentes padronizados, focando, pois, os benefícios da economia de escala. O estágio secundário, por sua vez, seria responsável pelas tarefas de diferenciação do produto para atender às necessidades individuais de cada cliente. O ponto no qual há a divisão entre a produção padronizada da customizada é denominado ponto de desacoplamento do pedido do cliente (customer order decoupling point) (VAN HOEK, 2001).

A postergação da logística ou distribuição, por seu turno, consiste em manter produtos acabados estocados em apenas um ou alguns locais estratégicos, onde os produtos são deslocados a partir do pedido do cliente. Apesar deste tipo de customização não influir na customização do produto, é por meio dele que se obtém redução dos níveis dos estoques ao longo da cadeia de suprimentos (PAGH; COOPER, 1998; YANG; BURNS; BACKHOUSE, 2004; WALLER; DABHOLKAR; GENTRY, 2000) e diminuição do tempo compreendido entre o pedido e a entrega dos produtos para os clientes (BOWERSOX; CLOSS, 2001).

Por outro lado, caso a empresa realize tanto as atividades de manufatura quanto de logística ou distribuição contrapedidos dos clientes, significa que ela executa a estratégia de postergação plena, a qual representa o mais alto nível de aplicação da postergação (PAGH; COOPER, 1998).

Desta forma, a execução do conceito de postergação ao longo da cadeia de suprimentos permite obter benefícios associados às economias de escopo e redução da complexidade da manufatura (DORNIER et al., 2000), menor dependência do sistema de distribuição em relação à previsão da demanda, aumento da flexibilidade e redução tanto dos custos de transporte como de manutenção de estoques (ZINN, 1990).

Neste contexto, a postergação de tarefas ao longo da cadeia de suprimentos constitui uma das estratégias passíveis de ser adotadas para o alcance dos objetivos da customização em massa (FEITZINGER; LEE, 1997; VAN HOEK; COMMANDEUR; VOS, 1998; VAN HOEK; PEELEN; COMMANDEUR, 1999; VAN HOEK; 2001; CARMO; GAVRONSKI, 2002; BERMAN, 2002; HERMANSKY; SEELMANN-EGGEBERT, 2003; YANG; BURNS; BACKHOUSE, 2004).

Evidencia-se assim, após a revisão bibliográfica sobre as estratégias de customização em massa, que a adoção de componentes padronizados modulares, associada à postergação da montagem, parece ser uma abordagem apropriada para alcançar, concomitantemente, maior variedade de produtos, menores custos e volumes elevados de produção.

$\mathrm{O}$ uso de módulos colabora para otimizar não apenas as atividades de montagem, mas também favorece a disponibilização de produtos que possam ser configurados pelos próprios consumidores, de modo a atenderem a suas próprias necessidades. Esta abordagem, contudo, pressupõe que o número de atributos passíveis de ser customizados seja limitado ao resultado das possíveis permutações de componentes modulares projetados e aos produtos aos quais serão agregados.

A seção seguinte tem o objetivo de esclarecer os procedimentos metodológicos adotados nesta pesquisa.

\section{PROCEDIMENTOS METODOLÓGICOS}

\section{Estratégia de pesquisa e critérios para escolha de casos e sujeitos da pesquisa}

Devido à natureza do problema, esta pesquisa utilizou estudos de casos múltiplos. No intuito de proporcionar uma visão ampla do fenômeno em estudo, por sua vez, foram 
selecionadas e pesquisadas 15 empresas (Quadro 2), abrangendo nove diferentes divisões de atividades econômicas, conforme Classificação Nacional de Atividades Econômicas (CNAE) elaborada pelo Instituto Brasileiro de Geografia e Estatística (IBGE, 2004). Tais empresas estão localizadas, principalmente, em três estados brasileiros: Rio Grande do Sul, Santa Catarina e São Paulo.

O número de empresas alvo do estudo decorreu da disponibilidade de acesso e recursos, bem como da complexidade envolvida para coleta e investigação apurada dos dados, que consistirá, como será oportunamente detalhado, de múltiplas fontes de evidência e fases de análise. $\mathrm{O}$ fato de estarem situadas no país, por sua vez, está associado à carência de estudos mais aprofundados, no âmbito nacional, sobre as estratégias de customização em massa, ao mesmo tempo em que tem o intuito de viabilizar, economicamente, a implementação da estratégia de pesquisa escolhida.

Além da localização, quatro outros critérios (não mutuamente exclusivos) foram empregados na seleção das empresas: pertencer às indústrias de transformação e construção civil; apresentar procedimentos documentados sobre o uso da estratégia de customização em massa; adotar, se possível, diferentes estágios de customização dos produtos; e serem potenciais customizadoras na percepção de experientes pesquisadores convidados a opinar a este respeito.

Para obtenção dos dados necessários, os sujeitos-alvo da pesquisa foram os executivos das empresas selecionadas, uma vez que, em princípio, os mesmos detêm a mais completa informação acerca do tema objeto da investigação. O número de integrantes da pesquisa, por sua vez, foi baseado no potencial de contribuição informacional de cada respondente para o desenvolvimento de insights e entendimento do fenômeno (MERRIAM, 1998).

Assim, de modo a se obter uma ampla percepção do fenômeno pesquisado, sempre que possível, foram escolhidos profissionais alocados em diferentes áreas funcionais, tais como produção, engenharia, logística, marketing e desenvolvimento de produto.

\section{Instrumentos de coleta de dados, pré-teste e estudo piloto}

Inicialmente, para a coleta dos dados secundários, foi realizada uma extensa pesquisa bibliográfica em livros, monografias, dissertações, teses, artigos dispostos em anais de congressos e encontros, revistas e jornais nacionais e internacionais das áreas de administração, economia e engenharia de produção, de modo a propiciar um exame, o mais completo possível, referente ao estudo pertinente ao tema. Para dar o suporte necessário à obtenção de artigos internacionais, foram utilizadas as bases de dados EBSCO e ProQuest.
Para a coleta de dados primários, por seu turno, foi realizada uma pesquisa de campo exploratória no parque fabril das empresas que contemplaram as características necessárias para a consecução do estudo. Neste caso, foram utilizadas várias fontes de evidência, tais como observação, documentos, registros e entrevistas semi-estruturadas (adotadas como principal técnica de coleta de dados), as quais foram utilizadas no processo de triangulação de dados.

Durante as entrevistas, foi seguido um roteiro de tópicos relativos ao problema em enfoque, onde o pesquisador teve a liberdade de sondar razões e motivos que sustentassem determinadas decisões por parte da empresa. Para otimizar este procedimento, e com a devida permissão dos entrevistados, todas as entrevistas foram gravadas em fita cassete para posterior transcrição. $\mathrm{O}$ roteiro de entrevista elaborado, por seu turno, foi previamente testado por um conjunto de cinco especialistas que possuíam experiência no desenvolvimento de estudos qualitativos em organizações (MACHADO, 2005).

\section{A s empresas selecionadas apresentam diferentes graus de customização produtos comercializados.}

Ademais, foram conduzidos estudos pilotos em duas empresas selecionadas segundo os critérios já apresentados, em conjunto com a conveniência geográfica e a facilidade de acesso aos dados. Assim, por meio da execução dos casospiloto, e em consonância com as observações de Marconi e Lakatos (2001), tornou-se possível evidenciar as reações dos entrevistados, suas dificuldades de entendimento, suas tendências para se esquivarem de questões delicadas, além da ambigüidade das perguntas, existência de questões supérfluas, adequação ou não da ordem de sua apresentação, se eram muito numerosas ou, ao contrário, necessitavam ser complementadas.

Concluídos os procedimentos de planejamento da pesquisa, foram realizados, inicialmente, contatos telefônicos, e por e-mail, com representantes das empresas-alvo da investigação. Em seguida, as questões centrais envolvidas no roteiro de entrevista, juntamente com uma carta de apresentação, foram enviadas aos respondentes da pesquisa.

\section{Análise dos dados}

Em estudo de casos múltiplos, há dois estágios de análise: a análise individual dos casos e a análise cruzada dos casos (MERRIAM, 1998; YIN, 2001). Para a execução da análise individual dos casos, inicialmente, foi realizada uma pré-análise dos dados coletados a fim de identificar a possibilidade de agrupá-los em categorias. 
Neste sentido, emergiram oito categorias primárias de análise: caracterização da empresa, fatores que motivaram a empresa a empreender esforços para customização dos produtos, processo de customização, estágios onde ocorrem a customização, critérios para seleção dos componentes dos produtos a serem customizados, estratégias de customização em massa, habilitadores da customização em massa, e principais dificuldades para implementação da customização em massa. Em seguida, para cada empresa, foi realizada uma explanação a respeito das respectivas categorias.

Concluída esta primeira fase, foram elaborados relatórios distintos, por empresa, contendo os resultados individuais da análise realizada. Cada relatório foi enviado (via e-mail) para os respectivos entrevistados de cada empresa pesquisada. Por meio de uma carta, anexada a cada relatório, foi solicitado que se fizesse uma avaliação a respeito da análise dos dados desenvolvida, com o objetivo de verificar a conformidade dos resultados à realidade observada. Pretendeuse, por meio deste procedimento, contribuir para o alcance da validade interna dos dados.
De posse dos comentários realizados pelos entrevistados, o pesquisador revisou os resultados das análises individuais das empresas, de modo a torná-los mais realistas. Em seguida, as descobertas relacionadas a cada uma das categorias dos casos individuais foram comparadas entre si, por meio da análise cruzada dos casos, no intuito de identificar a existência de similaridades ou diferenças entre os padrões de respostas associados a cada empresa. Estes esforços estão vinculados à obtenção da validade externa dos resultados.

Os resultados emergentes das evidências empíricas, decorrentes da análise cruzada dos casos, por sua vez, foram confrontados com os elementos teóricos colhidos na literatura especializada, a fim de identificar oportunidades para o desenvolvimento da teoria sobre o tema da pesquisa.

Para os propósitos deste artigo, a próxima seção tem o intuito de apresentar os resultados da análise cruzada dos casos pesquisados abrangendo três das oito categorias supracitadas. A análise contemplando todas as categorias, bem como as análises individuais dos casos, pode ser observada em Machado (2005).

\section{Quadro 2: Empresas Pesquisadas.}

\begin{tabular}{|c|c|}
\hline EMPRESA & ATIVIDADE EGONÔMIGA \\
\hline Randon S.A. (Divisão de Implementos) & Fabricação e montagem de veículos automotores, reboques e carrocerias \\
\hline Scania & Fabricação e montagem de veículos automotores, reboques e carrocerias \\
\hline Vanbro Bombas Submersas & $\begin{array}{l}\text { Fabricação de motores, bombas, compressores e equipamentos de } \\
\text { transmissão }\end{array}$ \\
\hline Weg & Fabricação de máquinas, aparelhos e materiais elétricos \\
\hline Tevah & Confecção de artigos do vestuário e acessórios \\
\hline Closet & Confecção de artigos do vestuário e acessórios \\
\hline Capa Engenharia & Construção \\
\hline Klabin Segall Engenharia & Construção \\
\hline Empresa X (identificação sigilosa] & $\begin{array}{l}\text { Preparação de couros e fabricação de artefatos de couro, artigos de } \\
\text { viagem e calçados }\end{array}$ \\
\hline Felix Formas e Componentes & $\begin{array}{l}\text { Preparação de couros e fabricação de artefatos de couro, artigos de } \\
\text { viagem e calçados }\end{array}$ \\
\hline Killing S.A. Tintas e Solventes & Fabricação de produtos químicos \\
\hline Marsul Proteínas Ltda. & Fabricação de produtos químicos \\
\hline $\begin{array}{l}\text { Empresa } Y \\
\text { (identificação sigilosa] }\end{array}$ & Fabricação de máquinas para escritórios e equipamentos de informática \\
\hline Todeschini & Fabricação de móveis e indústrias diversas \\
\hline Happy Town & Fabricação de móveis e indústrias diversas \\
\hline
\end{tabular}

Fonte: pesquisa de campo; IBGE, 2004, p. 36-64 


\section{RESULTADOS DA ANÁLISE CRUZADA DOS CASOS}

\section{Caracterização das empresas}

Conforme foi possível constatar por meio dos dados coletados, $53 \%$ das empresas disponibilizam a totalidade dos seus produtos customizados para seus clientes; $40 \%$ das empresas comercializam entre $60 \%$ e $80 \%$ de produtos de forma customizada; e apenas $7 \%$ delas customizam menos do que $50 \%$ do volume total de produtos produzidos.

Observa-se também que aproximadamente $46,6 \%$ das empresas apresentam um número inferior a 150 empregados; $26,7 \%$ possuem entre 400 e 800 empregados, mesmo percentual também encontrado para as empresas que têm acima de 2.000 empregados. Ao se analisar aquelas empresas com menos de 150 empregados, por seu turno, verifica-se que $43 \%$ delas possuem, no máximo, 50 empregados.

Por fim, a percepção de que certas empresas pesquisadas adotam o modelo de venda direta, lidam com mercados industriais, fabricam produtos usando componentes modulares, e possuem clientes exigentes e insatisfeitos com o desempenho dos produtos e serviços oferecidos no mercado de forma padronizada, por exemplo, vai ao encontro dos requisitos propostos por Berman (2002) para identificar as empresas que estariam mais aptas a adotar a estratégia de customização em massa em seus negócios.

\section{Estágios onde ocorre a customização}

As empresas pesquisadas executam atividades associadas à customização dos seus produtos em diferentes estágios da cadeia de valor, sendo que a maioria das empresas oferece, pelo menos, dois níveis de customização para o mercado.

Estes resultados estão em consonância com os resultados das pesquisas empreendidas por Carmo e Gavronski (2002) e MacCarthy, Brabazon e Bramham (2003), os quais destacaram haver mais de um nível de customização proporcionado por uma empresa a seus clientes. O número de níveis de customização parece ser decorrente dos atributos do produto ou serviço a serem customizados e do grau de envolvimento do cliente no processo de personalização, a fim de não comprometer o desempenho do sistema produtivo.

Neste contexto, a maioria das empresas customiza nos estágios (não mutuamente exclusivos) de projeto, fabricação e montagem, sendo a fabricação o estágio mais comumente utilizado nas atividades de customização. Isto acontece porque todas as vezes que há a exigência de realizar a elaboração de um novo projeto ou a adequação do mesmo, ocorre a necessidade de também realizar atividades diferenciadas na fase de fabricação.
Ademais, ainda que não seja obrigatória a realização de modificações no projeto, muitas vezes, torna-se imprescindível realizar certos ajustes (em termos dimensionais, por exemplo) ou modificar alguma característica do componente do produto para se atender adequadamente ao pedido do cliente.

Além disto, diferente do que sugeriram Lampel e Mintzberg (1996), o fato de existir customização em determinados estágios à montante do processo não implica que as atividades mais próximas do cliente também sejam customizadas. Isto fica claro quando se constata que Tevah, Closet, Killing, Marsul, Felix, Capa Engenharia e a Klabin Segall, por exemplo, não lidam com customização na fase de montagem, anda que customizem o projeto e no estágio de fabricação. 
Por sua vez, a Empresa Xé aquela que possui o maior grau de customização entre as demais analisadas, pois além de atender às necessidades dos clientes nos estágios de projeto, fabricação e montagem, de forma semelhante a Randon, Scania, Vanbro e Weg, ela também oferece, diferentemente destas últimas, serviços adicionais de personalização, aumentando, portanto, o número de alternativas de diferenciação para o mercado.

Desta forma, a escolha a respeito do grau de customização apresenta implicações sobre o conjunto de atividades desempenhadas pela empresa para o atendimento dos pedidos dos clientes e, por conseguinte, indica quais habilidades devem ser desenvolvidas internamente para alcançar este objetivo.

Por outro lado, constata-se, em consonância com Amaro, Hendry e Kingsman (1999), que uma mesma empresa pode possuir diferentes graus de customização. Afinal, devido às necessidades diferenciadas de cada cliente, os pedidos podem ser atendidos a partir de estágios distintos que compõem a cadeia de valor, possibilitando que uma empresa execute as atividades de customização apenas no estágio de distribuição (baixo grau de customização), ainda que tenha potencial para oferecer novos desenvolvimentos ou alterações dos projetos originais (alto grau de customização).

Neste contexto, apesar de oferecer produtos que podem ser customizados desde o projeto, percebe-se que as empresas têm empreendido esforços para atender aos pedidos dos clientes, preferencialmente, nos estágios mais à jusante do processo produtivo. Isto pode ocorrer nas atividades envolvidas com a fabricação, montagem, embalagem ou distribuição, com o intuito de reduzir o tempo e a complexidade exigida, sob a perspectiva da customização em massa.

\section{Estratégias de customização em massa implementadas por empresas brasileiras}

Ao se analisar as ações empreendidas no processo de customização dos produtos e serviços das empresas selecionadas, constata-se, como pode ser observado no Quadro 3, que duas estratégias se sobressaem: modularidade e postergação da manufatura. Todavia, o uso de componentes modulares, sem o retardamento das atividades de diferenciação do produto até o recebimento do pedido do cliente, não se configura em customização, mas sim em uma estratégia para propiciar o aumento da variedade de opções ao mesmo tempo em que reduz a complexidade do produto e do processo (BALDWIN; CLARK, 1997).

Por outro lado, o fato de atrasar o início das tarefas de manufatura ou logística até o recebimento do pedido de um cliente específico não implica, necessariamente, que uma empresa esteja customizando seus produtos por meio de uma estratégia de postergação (WALLER; DABHOLKAR; GENTRY, 2000). Logo, as estratégias de modularização e postergação devem ser adotadas, concomitantemente, pelas empresas que almejam a customização em massa.

O uso da produção modular difere de acordo com o tipo de modularidade empregada para prover produtos customizados e, por sua vez, o tipo de modularidade depende das características do projeto do produto. Nesta perspectiva, a análise cruzada dos casos permitiu identificar a existência de alguns padrões na utilização dos tipos de modularidade adotados pelas empresas.

A Randon e a Scania, representantes do setor automobilístico, por exemplo, executam a modularização por bus, a qual é caracterizada pela existência de uma estrutura padronizada (neste caso o chassi) que pode receber um número de diferentes tipos de componentes que se conectam utilizando o mesmo tipo de interface.

A Vanbro (fabricantes de motores e bombas) e a WEG (fabricante de motores e materiais elétricos) utilizam a modularidade por compartilhamento de componentes, ou seja, um mesmo componente pode ser utilizado ao longo de múltiplos produtos para permitir a produção de baixo custo de uma grande variedade de produtos.

Tanto a Tevah quanto a Closet, devido à necessidade de ajustar as dimensões físicas das partes componentes dos modelos ofertados às medidas do corpo de cada cliente, adotam a modularidade por ajuste de componentes. Este tipo

Figura 2: Grau de customização das empresas selecionadas.

\begin{tabular}{|c|c|c|c|c|c|c|c|}
\hline \multicolumn{8}{|c|}{ Grau de Customização } \\
\hline Happy Town & Empresa Y & Todeschini & $\begin{array}{c}\text { Tevah } \\
\text { Closet } \\
\text { Capa } \\
\text { Engenharia } \\
\text { Felix }\end{array}$ & Klabin Segall & Marsul & $\begin{array}{l}\text { Randon } \\
\text { Scania } \\
\text { Vanbro } \\
\text { WEG }\end{array}$ & Empresa X \\
\hline
\end{tabular}


de modularidade é usado quando é exigido que os produtos tenham dimensões físicas únicas, e foi destacado por Pine (1994) no caso da customização de bicicletas realizada pela empresa japonesa National Bicycle Industrial Company.

Por razões semelhantes, a Todeschini também adota a modularidade por ajuste de componentes, na medida em que lida com a necessidade de ajustar as dimensões (em termos de comprimento) dos tampos e prateleiras lineares, no estágio de fabricação, para atender às especificações individuais dos clientes. Além disso, no estágio de montagem, a empresa utiliza a modularidade seccional, possibilitando a combinação de diferentes peças (que compõem modelos diversos) por meio de encaixes e conexões padrões.

A Killing e a Marsul, por seu turno, usam a modularidade por mix, uma vez que quando os itens componentes são combinados, eles não se tornam mais visíveis no produto final. Desta forma, no caso das tintas comercializadas pela Killing, a combinação adequada de bases e pigmentos permite a produção de tintas com características físico-químicas diferenciadas. Em relação à Marsul, a partir da mistura específica de matérias-primas e produtos texturizados, são gerados formulados protéicos para atender às necessidades individuais de hidratação, emulsificação de gorduras e aumento de valor nutricional.

A Empresa Y, Happy Town e a Empresa X têm em comum o fato de empregarem a modularização por permuta de componentes. Desta forma, o número de alternativas de configurações possíveis é decorrente do emparelhamento de componentes diferentes em um mesmo produto básico, que pode corresponder ao chassi do computador (Empresa Y), boneco de pelúcia (Happy Town) ou formas e solados (Empresa X).

Os tipos individuais de modularidade destacados para a maioria das empresas, entretanto, não querem dizer que as mesmas adotem apenas uma modalidade. Ao contrário disto, percebe-se que as empresas utilizam um conjunto de tipos diferentes e complementares de modularidade. É o caso da modularidade por compartilhamento de componentes, que

\section{Quadro 3: Estratégias de customização em massa.}

\begin{tabular}{|c|c|}
\hline EMPRESA & ESTRATÉGIA DE CUSTOMIZAÇÃO EM MASSA \\
\hline Randon (Divisão de Implementos] & Modularidade por bus; Postergação da montagem \\
\hline Scania & Modularidade por bus; Postergação da fabricação e da montagem \\
\hline Vanbro Bombas Submersas & $\begin{array}{l}\text { Modularidade por compartilhamento de componentes; Postergação da } \\
\text { fabricação e da montagem }\end{array}$ \\
\hline Weg & $\begin{array}{l}\text { Modularidade por compartilhamento de componentes; Postergação da } \\
\text { fabricação e da montagem }\end{array}$ \\
\hline Tevah & Modularidade por ajuste de componentes; Postergação da fabricação \\
\hline Closet & Modularidade por ajuste de componentes; Postergação da fabricação \\
\hline Capa Engenharia & $\begin{array}{l}\text { Customização pura em conjunto com esforços associados ao aumento da } \\
\text { flexibilidade do projeto e da construção }\end{array}$ \\
\hline Klabin Segall & $\begin{array}{l}\text { Customização pura em conjunto com esforços associados ao aumento da } \\
\text { flexibilidade do projeto e da fabricação; Serviços adicionais }\end{array}$ \\
\hline Empresa $\mathrm{X}$ & $\begin{array}{l}\text { Modularidade por permuta de componentes; Postergação da fabricação e da } \\
\text { montagem; Serviços adicionais }\end{array}$ \\
\hline Felix Formas e Componentes & Customização pura em conjunto com esforços para prover respostas rápidas \\
\hline Killing S.A. Tintas e Solventes & Modularidade por mix; Postergação da fabricação \\
\hline Marsul & Modularidade por mix; Postergação da fabricação e da embalagem \\
\hline Empresa $Y$ & Modularidade por permuta; Postergação da montagem; Serviços Adicionais \\
\hline Todeschini & $\begin{array}{l}\text { Modularidade por ajuste de componentes e modularidade seccional; } \\
\text { Postergação da fabricação e da montagem }\end{array}$ \\
\hline Happy Town & Modularidade por permuta; Postergação da montagem; Serviços adicionais \\
\hline
\end{tabular}


pode ser adotada por todas as empresas, com o objetivo de proporcionar economias de escopo. A seleção de um tipo particular para cada empresa, por sua vez, foi decorrente do grau de importância da respectiva modularidade para alcançar os objetivos das estratégias de customização em massa.

A utilização da estratégia de modularização foi destacada por vários estudiosos do fenômeno da customização em massa (SPIRA, 1993; PINE, 1994; LAMPEL; MINTZBERG, 1996; DURAY et al., 2000; ALFORD; SACKETT; NELDER, 2000; SILVEIRA; BORESTEIN; FOGLIATTO, 2001) em seus respectivos trabalhos. Contudo, Spira (1993) e Silveira; Borestein e Fogliatto (2001), por exemplo, limitaram o uso de módulos às atividades de montagem dos produtos, não contemplando sua utilização no estágio de fabricação.

Gilmore e Pine (1997), por seu turno, nem sequer salientaram a importância do uso de módulos em suas respectivas abordagens. Além disto, apenas Duray et al. (2000) consideraram os tipos de modularidade como uma das variáveis para classificar as categorias da estratégia de customização em massa.

O tipo de postergação adotado, por sua vez, varia de empresa para empresa e depende, principalmente, da natureza do produto e da localização do ponto de desacoplamento do pedido do cliente no processo produtivo. Desta forma, uma vez que a maioria das empresas retarda a finalização da fabricação do produto para o momento após o recebimento do pedido do cliente, o tipo de postergação mais comumente adotado foi a postergação da fabricação.

Assim, além da modularidade, a postergação da fabricação foi a estratégia adotada pela Tevah, Closet e Killing para customização em massa dos seus produtos. Ademais, algumas empresas (Scania, Vanbro, Empresa X, Todeschini), não apenas utilizaram componentes modulares e postergaram a fabricação, como também atrasaram as atividades de montagem para depois da definição dos atributos do produto final pelos clientes.

A Marsul, por outro lado, não apenas posterga a fabricação, como também adia a tarefa de embalar o produto até a definição das necessidades do cliente. Esta estratégia de customização apenas foi contemplada por Spira (1993), Gilmore e Pine (1997) e Silveira; Borestein e Fogliatto (2001).

A Happy Town, a Empresa Y e a Randon, por sua vez, além da estratégia de modularização, postergam a montagem dos respectivos produtos no intuito de reduzir o tempo e os custos associados à customização em massa.

Os diferentes tipos de postergação implementados pelas empresas analisadas (postergação da fabricação, montagem e embalagem) são contemplados por Zinn (1990) e compreendidos como categorias de postergação da manufatura. A distinção entre estas categorias é importante, sobretudo, porque revela quais os estágios da manufatura nos quais ocorre a customização.

Todavia, diversos autores (FEITZINGER; LEE, 1997; VAN HOEK; COMMANDEUR; VOS, 1998; PAGH; COOPER, 1998; VAN HOEK; PEELEN; COMMANDEUR, 1999; VAN HOEK; 2001; BOWERSOX; CLOSS, 2001; CARMO; GAVRONSKI, 2002; HERMANSKY; SEELMANN-EGGEBERT, 2003; YANG; BURNS; BACKHOUSE, 2004) trataram a postergação na área produtiva de forma genérica, sem distinção de categorias, impossibilitando, pois, a clara identificação das atividades envolvidas na customização.

Ademais, nenhum dos trabalhos (identificados e analisados nesta pesquisa) que se propuseram delinear as possíveis abordagens para customização em massa (como por exemplo: SPIRA, 1993; PINE, 1994; LAMPEL; MINTZBERG, 1996; DURAY et al., 2000; ALFORD; SACKETT; NELDER, 2000; SILVEIRA; BORESTEIN; FOGLIATTO, 2001), contemplou a postergação da manufatura como uma das estratégias de customização em massa.

Por outro lado, de forma similar ao que já havia sido constatado por Spira (1993), Pine (1994), e Silveira, Borestein e Fogliatto (2001) em suas respectivas pesquisas, quatro das empresas selecionadas disponibilizam serviços adicionais de customização para seus clientes como forma de complementar as estratégias de customização implementadas.

Os serviços adicionais de customização envolvem: a possibilidade de anexar etiquetas de preços ou códigos de barras específicos para cada cliente (Empresa X); instalação de softwares, imagens e etiquetas de identificação (Empresa Y); bordado de caracteres, gravação de mensagens, cartão personalizado (Happy Town); e instalação de armários, arcondicionado, aquecedor, luminárias, cortinas e box (Klabin Segall).

A adoção de serviços adicionais, contudo, não foi contemplada nos trabalhos de alguns autores envolvidos com a o estudo da customização em massa (como por exemplo: PINE, 1994; LAMPEL; MINTZBERG, 1996; FEITZINGER; LEE, 1997; VAN HOEK; COMMANDEUR; VOS, 1998; VAN HOEK; PEELEN; COMMANDEUR, 1999; DURAY et al., 2000; ALFORD; SACKETT; NELDER, 2000; VAN HOEK; 2001; CARMO; GAVRONSKI, 2002; BERMAN, 2002; HERMANSKY; SEELMANN-EGGEBERT, 2003; YANG; BURNS; BACKHOUSE, 2004).

Por fim, o fato de as empresas, em situações particulares, permitirem o envolvimento do cliente desde a fase do projeto, não implica que a adoção de estratégias de customização em massa contemple este nível. Afinal, customizar na fase de projeto do produto requer o desenvolvimento de novos produtos ou a adequação do projeto original para atender às necessidades específicas dos clientes. 
Ambos os casos demandam tempo e custo elevados, decorrentes das tarefas de análise de viabilidade técnica, mercadológica, financeira e, em certos casos, legal. Além disto, a customização do projeto resulta em maior complexidade para fabricação e gera forte impacto sobre as atividades logísticas. Como conseqüência, os volumes produzidos tendem a ser menores e os preços dos produtos finais são maiores. Logo, ainda que a customização, a partir do projeto, tenha sido contemplada por certos autores (tais como: LAMPEL; MINTZBERG, 1996; GILMORE; PINE, 1997; DURAY et al., 2000; ALFORD; SACKETT; NELDER, 2000; SILVEIRA; BORESTEIN; FOGLIATTO, 2001), esta abordagem vai de encontro aos objetivos da customização em massa.

A seguir, serão apresentadas algumas conclusões desta pesquisa.

\section{CONCLUSÕES}

Por meio da análise dos casos, há indícios de que a adoção das estratégias de customização em massa não seja privilégio de grandes empresas, dotadas de muitos funcionários e capital para investimento. Micro e pequenas empresas também podem usufruir os benefícios advindos da customização em massa, desde que adotem métodos de gestão e ações apropriadas para o alcance dos seus objetivos.

Evidenciou-se que a maioria das empresas pesquisadas executa suas atividades de customização em diferentes estágios da cadeia de valor, oferecendo, pelo menos, dois níveis de customização para o mercado. O número de níveis de customização, por seu turno, parece ser decorrente dos atributos do produto ou serviço a serem customizados e do grau de envolvimento do cliente no processo de personalização, a fim de não comprometer o desempenho do sistema produtivo.

Por meio da análise do grau de envolvimento do cliente nas atividades que compõem a cadeia de valor de cada empresa, foi possível compreender as diferenças entre o grau de customização de cada empresa analisada. Desta forma, evidenciou-se que a maioria das empresas apresenta graus de customização diferentes.

O exame do processo implementado para a execução da customização em massa pelas empresas selecionadas contribuiu para compreender as ações empreendidas e identificar as diferenças entre as estratégias de customização adotadas. Assim, para contornar os problemas oriundos do aumento da variedade dos produtos e da complexidade para sua fabricação, as empresas têm se esforçado para utilizar componentes e estruturas previamente configurados, bem como selecionar componentes que possam ser intercambiados ao longo das opções de configuração disponibilizadas para o mercado.

A possibilidade de lidar com produtos que possam ser configurados, rapidamente e a baixos custos, a partir de ajustes ou combinações de componentes padronizados permite obter economias de escala e escopo, fundamentais para o objetivo da estratégia de customização em massa. Nesta perspectiva, duas estratégias se sobressaíram: modularidade e postergação da manufatura. Constatou-se, ainda, que o alcance dos objetivos da diferenciação a custos baixos é decorrente da utilização combinada das duas estratégias e não apenas da execução de uma delas em particular.

O uso da produção modular, por sua vez, difere de acordo com o tipo de modularidade empregada para prover produtos customizados, e o tipo de modularidade depende das características do projeto do produto. Percebeu-se, também, que as empresas utilizam um conjunto de tipos diferentes e complementares de modularidade para lidar com as necessidades operacionais específicas para disponibilização de seus produtos. Ademais, o uso do conceito de modularidade pode não apenas ser usado no estágio de montagem, mas também, anteriormente, na fabricação.

\section{\s estratégias de modularização e postergação - devem ser adotadas, concomitantemente, pelas empresas que almejam a customização em massa.}

A existência de pontos de desacoplamento do pedido do cliente (customer order decoupling point), decorrentes da divisão do processo produtivo em, pelo menos, dois estágios (primário e secundário), também é essencial para os propósitos da customização em massa. Neste sentido, o estágio primário seria responsável pela produção de componentes padronizados, enquanto o estágio secundário seria responsável pelas tarefas de diferenciação do produto para atender às necessidades individuais de cada cliente.

Neste sentido, o tipo de postergação adotado varia de empresa para empresa e depende, principalmente, da natureza do produto e da localização do ponto de desacoplamento do pedido do cliente no processo produtivo. Desta forma, uma vez que a maioria das empresas retarda a finalização da fabricação do produto para o momento após o recebimento do pedido do cliente, o tipo de postergação mais comumente adotado foi a postergação da fabricação.

Como forma de complementar os esforços para a customização em massa dos produtos, além das estratégias implementadas, quatro das empresas selecionadas (Empresa X, Empresa Y, Happy Town e Klabin Segall) disponibilizam serviços adicionais de customização para seus clientes. 


\section{Artigo recebido em 10/04/2006 Aprovado para publicação em 13/12/2007}

\section{neferências}

ALFORD, D.; SACKETT, P.; NELDER, G. Mass customisation: an automotive perspective. International Journal of Production Economics, v. 65, p. 99-110, 2000.

BALDWIN, C. Y. CLARK, K. B. Managing in an age of modularity. Harvard Busines Review, p. 84-93, sep.-oct. 1997.

BERMAN, B. Should your firm adopt a mass customization strategy? Business Horizons, p. 51-60, jul.-aug. 2002.

BOWERSOX, D. J.; CLOSS, D. J. Logística empresarial: o processo de integração da cadeia de suprimento. São Paulo: Atlas, 2001

CARMO, F. D. C. F.; GAVRONSKI, I. Jit aproach to mass customization: a case study. In: ENCONTRO DA ASSOCIACÃO DOS PROGRAMAS DE PÓS-GRADUAÇÃO EM ADMINISTRAÇ̃̃, 26., 2002, Salvador. Anais... Bahia: ANPAD, 2002. 1CD.

DORNIER, P.; ERNST, R.; FENDER, M.; KOUVELIS, P. Logística e operações globais texto e casos. São Paulo: Atlas, 2000

DURAY, R.; WARD, P. T.; MILLIGAN, G. W.; BERRY, W. L. Approaches to mass customization: configurations and empirical validation. Journal of Operations Management, v. 18, p. 605-625, 2000.

FEITZINGER, E.; LEE, H. Mass customization at Hewlett-Packard: the power of postponement. Harvard Business Review, p. 116-121, jan./feb. 1997
GILMORE, J. H.; PINE, J. The four faces of mass customization. Harvard Business Review, p. 91-101, jan.-feb. 1997.

HERMANSKY, J.; SEELMANN-EGGEBERT, R. Manufacturing postponed. IEE Manufacturing Engineer, p. 38-41, aug./ sep. 2003

IBGE. Classificação Nacional de Atividades Econômicas. 2. ed. Rio de Janeiro, 2004. 316 p. Disponível em: http://www.ibge. gov.br/home/estatistica/economia/classificacoes/cnae 1.0 2ed/default.shtm. Acesso em 4 abr. 2005 .

JIAO, J.; MA, Q.; TSENG, M. M.; Towards high value-added products and services: mass customization and beyond. Technovation, p.1-13, 2001.

LAMPEL, J.; MINTZBERG, H. Customizing Customization. Sloan Management Review, v. 38 , n. 1, p. 21-29, fall, 1996 .

MACCARTHY, B.; BRABAZON, P. G.; BRAMHAM, J. Fundamental modes of operation for mass customization. International Journal of Production Economics, v. 85, p. 289-304, 2003.

MACCARTHY, B.; BRABAZON, P. G. In the business of mass customisation. IEE Manufacturing Engineer, p. 30-33, aug./ sep. 2003

MACHADO, A. G. C. Estratégias de customização em massa: evidências teóricoempíricas e proposição de um framework. 2005. 400 f. Tese (Doutorado em Administração) - Programa de
Pós-Graduação em Administração, Universidade Federal de Pernambuco, Recife, 2005.

MARCONI, M. A.; LAKATOS, E. M Metodologia do trabalho científico: procedimentos básicos, pesquisa bibliográfica, projeto e relatório, publicações e trabalhos científicos. 5. ed. São Paulo: Atlas, 2001

MERRIAM, S. B. Qualitative research and case study applications in education. JosseyBass: San Francisco, 1998.

PAGH, J. D.; COOPER, M. C. Supply chain postponement and speculation strategies: how to choose the right strategy. Journal of Business Logistics, v. 19, n. 2, p. 13-33, 1998.

PINE, B. J. Personalizando produtos e serviços - customização maciça. São Paulo: Makron Books, 1994.

PORTER, M. E. Vantagem Competitiva: criando e sustentando um desempenho superior. 22. ed. São Paulo: Campus, 1989.

SILVEIRA, G. da; BORENSTEIN, D. FOGLIATTO, F. S. Mass customization: literature review and research direction. International Journal of Production Economics, v. 72, p. 1-13, 2001

SPIRA, J. S. Mass customization through training at Lutron Electronics. Planning Review, v. 21 , n. 4 , p. $23-24$, jul./aug. 1993.
VAN HOEK, R. I. The rediscovery of postponement a literature review and directions for research. Journal of Operations Management, v. 19, p.161-184, 2001

VAN HOEK, R. I.; COMMANDEUR, H. R. VOS, B. Reconfiguring logistics systems through postponement strategies. Journal of Business Logistics, v. 19, n. 1 , p. 33-54, 1998.

VAN HOEK, R. I.; PEELEN, E.; COMMANDEUR, H. R. Achieving mass customization through postponement: a study of international channels, Journal of Customer Based Management, p. 1-22, fev. 1999.

WALLER, M. A.; DABHOLKAR, P. A.; GENTRY, J.J. Postponement, product customization, and market-oriented supply chain management. Journal of Business Logistics, v. 21, n. 2, p. 133-156, 2000.

YIN, R. K. Estudos de caso: planejamento e métodos. 2. ed. Porto Alegre: Bookman, 2001

YANG, B.; BURNS, N. D.; BACKHOUSE, C. J. Postponement: a review and an integrated framework. International Journal Operations and Production Management, v. 24, n. 5, p. 468-487, 2004.

ZINN, W. O retardamento da montagem final de produtos como estratégia de marketing e distribuição. Revista de Administração de Empresas, v. 30, n. 4, p. 53-59, out./dez. 1990.

\section{André Gustavo Carvalho Machado \\ UFPB}

Professor Adjunto

Av. Cabo Branco 1758/701 - Cabo Branco - João Pessoa-PB - CEP 58045-010

Fone (83) 3247-5474

E-mail: andregcm@terra.com.br

\section{Walter Fernando Araújo de Moraes \\ UFPE}

Professor Titular

Rua Moraes Rêgo, 1235 - Cidade Universitária - Recife-PE - CEP 50670-901

Fone: (81) 2126-7165

E-mail: wfam@br.inter.net 